\title{
ANALISIS KOEFISIEN ALIRAN PERMUKAAN PADA BERBAGAI BENTUK PENGGUNAAN LAHAN DENGAN MENGGUNAKAN MODEL SWAT
}

\section{ANALYSIS OF SURFACE RUNOFF COEFFICIENT ON VARIOUS LAND USING SWAT MODEL}

\author{
Danesta Ayu Saputri ${ }^{1 凶}$, Ridwan ${ }^{1}$, Mohamad Amin ${ }^{1}$, Sandi Asmara ${ }^{1}$ \\ ${ }^{1}$ Jurusan Teknik Pertanian, Fakultas Pertanian, Universitas Lampung \\ ${ }^{\square}$ Komunikasi Penulis, e-mail: danestaayusaputri@ymail.com \\ DOI: http://dx.doi.org/10.23960/jtep-l.v7i1.1-8 \\ Naskah ini diterima pada 2 Februari 2018; revisi pada 20 Februari 2018; \\ disetujui untuk dipublikasikan pada 2 April 2018
}

\begin{abstract}
Way Sekampung Hulu watershed definited as upstream part from Way Sekampung watershed with rain catchment area of 43,063 $\mathrm{km}^{2}$, that located in Tanggamus District of Lampung Province. Land shifting from non-building area to building area will stimulate the magnitude of surface water flow that impacts on the decline of recharge capacity and increased surface water flow that occurs flood in downstream area. The research aim to obtain the surface runoff coeffisient values in various lands use form of watershed and hydrograph river flow parameter values. The method of this research is approach of hydrology model analysis based GIS, with SWAT model. Data of river flow debit, rainfall, and climatology that used data record in 2010 until 2015. Process of model calibration with data record in 2010-2012 and model validation with data record in 2013-2015. Result of calibration process with SWAT-CUP was Nse and $R^{2}$ value for river flow debit (flow out) of 0.63 and 0.66 respectively. Result of model validation was Nse and $R^{2}$ value of 0.64 and 0.74 respectively. Surface flow coeffisient value (C) for shrubs of 0.13 , settlement of 0.22 , primary dryland forest of 0.11 , open land of 0.44 , moor of 0.28 and plantation of 0.15 . Analysis result also obtained best values for hydrograph flow parameters such as SURLAG of 0.389, GW_REVAP of 8.451, SOL_AWC of 1.104, EPCO of 0.008, HRU_SLP of 0.898, SLSBBSN of 23.195, CH_N2 of 3.876, ALPHA_BF of 0.636, GW_DELAY of 8.451, ESCO of 1.335 and $C N 2$ of 1.979.
\end{abstract}

Keywords: Land Use; Surface flow coefficient; SWAT Model,; Watershed.

\begin{abstract}
ABSTRAK
Daerah Aliran Sungai (DAS) Hulu didefinisikan sebagai bagian hulu dari DAS Way Sekampung, dengan luas daerah tampungan hujan sebesar $43.063 \mathrm{Km}^{2}$, yang berada di Kabupaten Tanggamus Provinsi Lampung. Perubahan penggunaan lahan dari lahan non terbangun menjadi terbangun akan menstimulisasi besarnya aliran air permukaan yang memberi dampak pada pengurangan kapasitas resapan pada satu sisi dan meningkatkan laju aliran permukaan pada sisi lain yang dapat berpotensi menyebabkan banjir di kawasan hilir. Tujuan penelitian ini adalah untuk memperoleh nilai koefisien limpasan permukaan pada berbagai bentuk penggunaan lahan DAS serta nilai-nilai parameter hidrograf aliran sungai. Metode penelitian menggunakan pendekatan analisis model hidrologi berbasis GIS, yaitu dengan model SWAT. Data debit aliran sungai, curah hujan dan klimatologi yang digunakan dalam penelitian adalah catatan tahun 2010 hingga 2015. Untuk proses kalibrasi model menggunakan data tahun 2010-2012, sedangkan validasi model menggunakan data tahun 2013-2015. Hasil proses kalibrasi menggunakan SWAT-CUP didapatkan nilai NSe dan $\mathrm{R}^{2}$ untuk variabel debit aliran sungai (flow out) masingmasing sebesar 0,63 dan 0,66. Adapun hasil validasi model didapatkan nilai NSe dan $\mathrm{R}^{2}$ sebesar 0,64 dan 0,74. Nilai koefisien aliran permukaan (C) untuk semak belukar sebesar 0,13 , pemukiman sebesar 0,22 , hutan lahan kering primer sebesar 0,11, tanah terbuka sebesar 0,44, tegalan sebesar 0,28 dan perkebunan sebesar 0,15. Hasil analisis juga memperoleh nilai-nilai terbaik untuk parameter hidrograf aliran meliputi, SURLAG sebesar 0,389, GW_REVAP sebesar 8,451,SOL_AWC sebesar 1,104,EPCO sebesar 0,008, HRU_SLP sebesar 0,898, SLSBBSN sebesar 23,195, CH_N2 sebesar 3,876, ALPHA_BF sebesar 0,636, GW_DELAY sebesar 8,451, ESCO sebesar 1,335 dan CN2 sebesar 1,979.
\end{abstract}

Kata kunci: Daerah Aliran Sungai; Koefisien Aliran Permukaan; Penggunaan Lahan; SWAT 


\section{PENDAHULUAN}

Penggunaan lahan merupakan salah satu faktor penting yang menentukan kondisi hidrologi suatu DAS. Perubahan penggunaan lahan pada suatu DAS akan menyebabkan terjadinya perubahan kondisi hidrologi DAS tersebut. Daerah Aliran Sungai (DAS) merupakan daerah yang dibatasi punggung gunung dimana air hujan yang jatuh akan ditampung dan dialirkan melalui sungai kecil menuju sungai utama. DAS memberikan pengaruh yang besar terhadap kebutuhan air baku dan berbagai kebutuhan air lainnya pada suatu daerah, sehingga dalam pengelolaannya dibutuhkan perencanaan yang sebaik mungkin (Rau, 2012). Pengelolaan daerah aliran sungai (DAS) merupakan pengaturan komposisi penggunaan lahan pada suatu DAS agar sumberdaya DAS dapat dimanfaatkan semaksimal mungkin tanpa menyebabkan terjadinya kerusakan pada DAS. Pengelolaan DAS dapat dilakukan dengan melakukan perencanaan yang optimal yang didasarkan pada kemampuan atau kondisi DAS dengan mempertimbangkan keseimbangan lingkungan (Broto, 2009).

Perubahan penggunaan lahan dari lahan non terbangun menjadi terbangun akan mestimulisasi besarnya aliran air permukaan yang memberi dampak pada pengurangan kapasitas resapan pada satu sisi dan meningkatkan laju aliran permukaan pada sisi lain yang dapat berpotensi menyebabkan banjir di kawasan hilir. Aliran permukaan merupakan komponen hidrologi terbesar yang berkontribusi dalam membentuk hidrograf aliran sungai. Oleh karena itu penelitian tentang besarnya nilai koefisien limpasan pada berbagai bentuk penggunaan lahan menjadi penting sebagai salah satu dasar pertimbangan di dalam pengelolaan Daerah Aliran Sungai. Tujuan penelitian ini adalah untuk memperoleh nilai koefisien limpasan permukaan pada beberapa bentuk penggunaan lahan DAS serta nilai-nilai parameter hidrograf aliran sungai DAS Way Sekampung Hulu.

\section{BAHAN DAN METODA}

\subsection{Bahan Penelitian}

Penelitian ini menggunakan data spasial berupa: 1) Peta rupa bumi wilayah Provinsi Lampung dengan skala 1:250.000,2) DEM (Digital Elevation Model) dengan resolusi 30 meter, 3) Peta tanah Provinsi Lampung dengan skala 1:50.000, 4) Peta tutupan lahan Provinsi Lampung, serta data empiris debit bulanan, curah hujan bulanan, klimatologi bulanan seperti temperatur, kelembaban udara, kecepatan angin dan, radiasi matahari dengan catatan data selama 5 tahun terakhir (2010-2015). Kegiatan penelitian dilakukan melalui beberapa tahapan yaitu, analisis konsistensi data pendukung model, simulasi model, kalibrasi dan validasi model serta analisis penentuan nilai koefisien limpasan permukaan. Model hidrologi yang digunakan dalam penelitian ini berupa model empiris SWAT berbasis GIS yang dijalankan dengan bantuan software ArcGIS 10.2 dan ArcSWAT 2012. Adapun proses kalibrasi dan validasi menggunakan model Sufi2 pada software SWAT CUP.

\subsection{Metode Penelitian}

Penelitian ini dilakukan dengan menggunakan model hidrologi berupa software SWAT. Model SWAT (Soil and Water Assessment Tools) merupakan salah satu model hidrologi yang telah terintegrasi dengan teknologi sisitem informasi geografi (SIG/GIS) sebagai ekstensi tambahan dari perangklat lunak ArcGIS 10.2. Model SWAT dijalankan dengan bantuan software ArcSWAT.

Penelitian ini dilakukan dengan mengikuti bagan alir penelitian sebagaimana disajikan pada Gambar 1.

\section{HASIL DAN PEMBAHASAN}

\subsection{Lokasi Penelitian}

Secara geografis lokasi penelitian berada pada garis meridian membentang dari 104을 BT hingga 10600' BT dan dari 0500 $00^{\prime}$ LS hingga 0505' LS, sehingga membentuk daerah tangkapan hujan seluas $43.063 \mathrm{~km}^{2}$ dengan ketinggian tempat antara $175 \mathrm{~m}$ hingga $1.775 \mathrm{~m}$ dari permukaan air laut. DAS Way Sekampung Hulu dibagi dalam 2 wilayah Sub DAS 


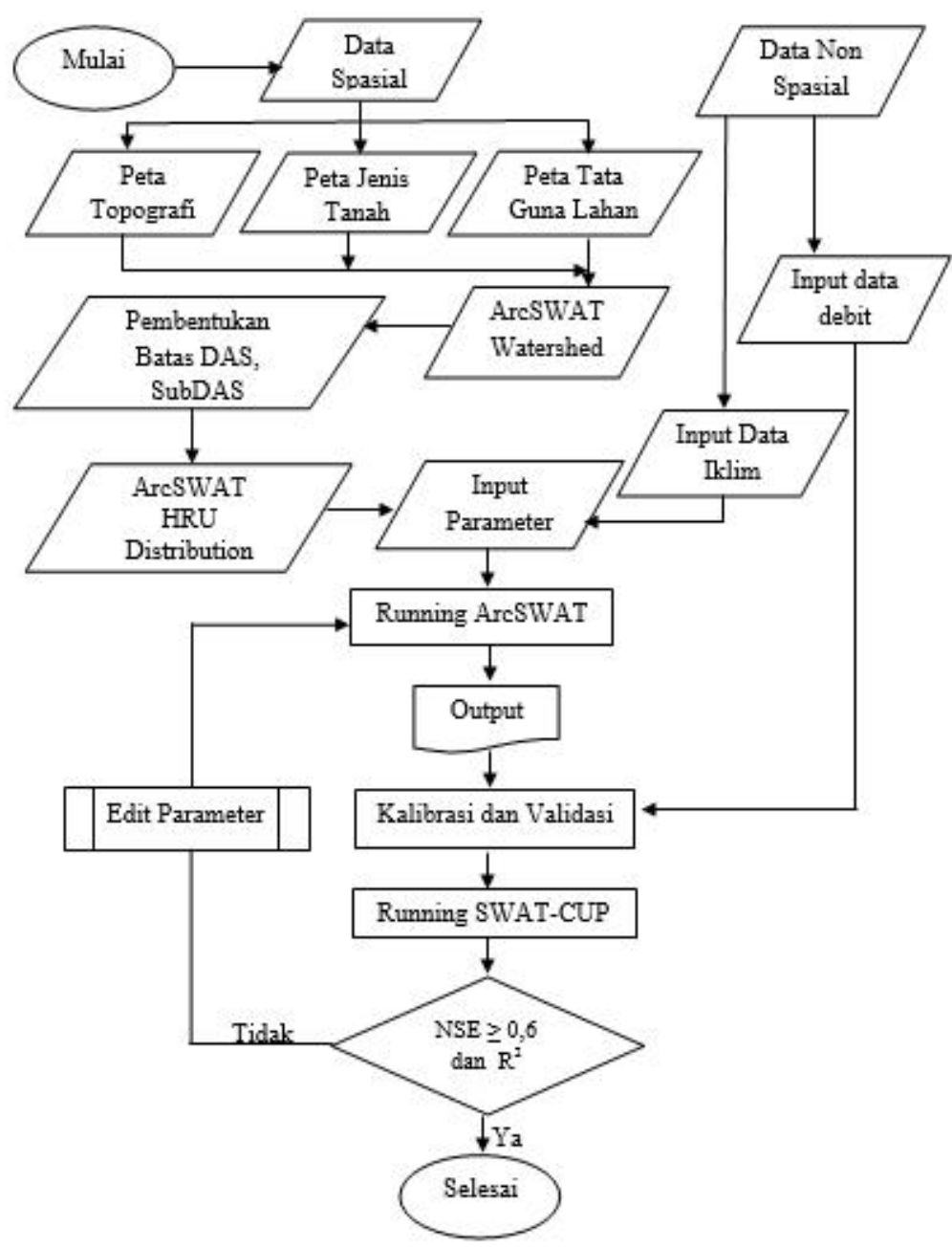

Gambar 1. Prosedur Analisis, kalibrasi dan validasi model SWAT

berdasarkan hasil analisis SWAT. Kondisi iklim di wilayah penelitian termasuk klasifikasi iklim tropis sepanjang tahun dengan temperatur udara relatif seragam dengan suhu rata-rata bulanan berkisar $26^{\circ} \mathrm{C}-27^{\circ} \mathrm{C}$, kelembaban rata-rata bulanan $79,5 \%$, kecepatan angin rata-rata sebesar 2,1 m/det, dan curah hujan tahunan mencapai $2.500 \mathrm{~mm}$.

\subsection{Jenis Tanah}

Berdasarkan analisa Peta Jenis Tanah Provinsi Lampung diketahui DAS Way Sekampung Hulu memiliki jenis tanah Aluvial, Andosol, Regosol, dengan sebaran yang dominan mencakup 2/3 dari luas DAS atau sebesar 38.115,23 ha, sedangkan jenis tanah lainnya adalah asosiasi Podsolik Merah Kuning dengan persebaran seluas 4.947,81 ha.

\subsection{Kelerengan}

Berdasarkan hasil analisis peta kemiringan lereng Provinsi Lampung tahun 2010, diketahui kelas kemiringan lereng pada DAS Way Sekampung Hulu secara umum didominasi oleh kelas lereng III (8-15\%) dengan luas area 12.674,46 ha.

\subsection{Penggunaan Lahan}

Penggunaan lahan DAS Way Sekampung Hulu dapat diidentifikasi ke dalam 8 jenis penggunaan yaitu sungai, danau, pemukiman, semak belukar, hutan lahan kering primer, tanah terbuka, tegalan, dan perkebunan. Berdasarkan identifikasi 2 jenis peta penggunaan lahan yang berbeda (tahun 2010 dan tahun 2015) diketahui terjadi perubahan luasan pada masing-masing penggunaan tersebut. Sebaran jenis penggunaan lahan dan perubahan luas cakupannya dalam daerah penelitian disajikan pada Tabel 1 .

\subsection{Pembentukan hidrograf respon unit (HRU)}

Pembentukan HRU dilakukan menggunakan ke 3 variabel lingkungan DAS yaitu jenis tanah, kemiringan lereng dan penutupan lahan pada 
Tabel 1. Sebaran Jenis Penggunaan Lahan DAS Way Sekampung Hulu Tahun 2010 dan 2015

\begin{tabular}{|c|c|c|c|c|c|c|}
\hline \multirow[b]{2}{*}{ Tata Guna Lahan } & \multirow[b]{2}{*}{ Simbol } & \multicolumn{2}{|l|}{2010} & \multicolumn{2}{|l|}{2015} & \multirow{2}{*}{$\begin{array}{c}\text { Perubahan } \\
\text { (\%) }\end{array}$} \\
\hline & & $\begin{array}{l}\text { Luas } \\
\text { (Ha) }\end{array}$ & $\begin{array}{c}\text { Luas } \\
(\%)\end{array}$ & $\begin{array}{l}\text { Luas } \\
\text { (Ha) }\end{array}$ & $\begin{array}{c}\text { Luas } \\
(\%)\end{array}$ & \\
\hline Sungai & SUNG & 296,85 & 0,69 & 85,91 & 0,20 & $-0,49$ \\
\hline Danau & DANA & $1.158,49$ & 2,69 & $1.582,93$ & 3,68 & 0,99 \\
\hline Pemukiman & URML & 26,38 & 0,06 & 96,12 & 0,22 & 0,16 \\
\hline Semak Belukar & SMBL & $7.422,99$ & 17,24 & $5.920,87$ & 13,75 & $-3,49$ \\
\hline $\begin{array}{l}\text { Hutan Lahan Kering } \\
\text { Primer }\end{array}$ & HLKP & $27.010,1$ & 62,72 & $33.402,2$ & 77,56 & 14,84 \\
\hline Tanah Terbuka & TNTB & 0 & 0 & 36,57 & 0,08 & 0,08 \\
\hline Tegalan & TGLN & 842,92 & 1,96 & 269.633 & 0,63 & $-1,33$ \\
\hline Perkebunan & PRKB & $6.305,33$ & 14,64 & $1.668,83$ & 3,88 & $-10,76$ \\
\hline Total Luas & & 43.063 & 100 & 43.063 & 100 & 0 \\
\hline
\end{tabular}

Sumber: Analisis SWAT, 2017.

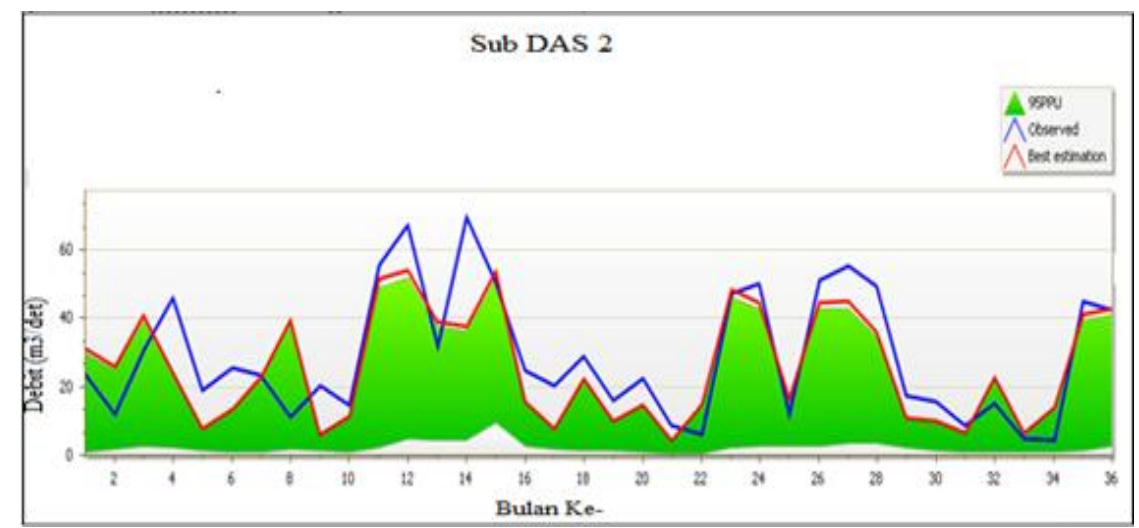

Gambar 2. Perbandingan Debit Observasi dan Debit Model Hasil Kalibrasi

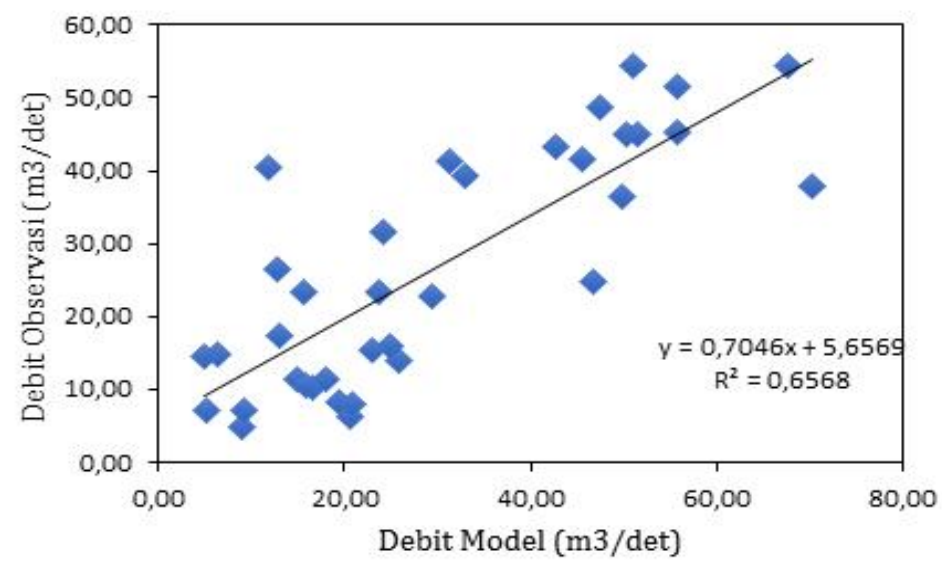

Gambar 3. Grafik XY Scatter antara Debit Observasi dan Debit Model

setiap sub DAS. Hasil analisis diperoleh pada tahun 2010 terbentuk 85 unit HRU, sedangkan pada tahun 2015 diperoleh 97 unit HRU.

\subsection{Hasil Kalibrasi Model}

Hasil kalibrasi model (Gambar 2) diperoleh nilai $P$-factor sebesar 0,39 (P-factor $<0,8), R$-factor sebesar 1,26 (R-factor $>1)$, nilai $\mathrm{R}^{2}$ sebesar 0,66 dan nilai NSe 0,63 . Persebaran perbandingan data debit observasi dengan debit model disajikan pada Gambar 3.

Proses kalibrasi menggunakan sebelas parameter yang berhubungan dengan aliran 
permukaan. Tingkat sensitivitas masing-masing parameter dapat dilihat pada Gambar 4. Gambar 4 tersebut menunjukkan bahwa parameter SURLAG memiliki nilai $P$-Value sebesar 0,99, GW_REVAP memiliki nilai $P$-Value sebesar 0,81 , SOL_AWC memiliki nilai $P$-Value sebesar 0,65, EPCO memiliki nilai $P$-Value sebesar 0,61 , HRU_SLP memiliki nilai P-Value sebesar 0,60, SLSBBSN memiliki nilai $P$-Value sebesar 0,34, CH_N2 memiliki nilai P-Value sebesar 0,32 , ALPHA_BF memiliki nilai $P$-Value sebesar 0,30, GW_DELAY memiliki nilai P-Value sebesar 0,044, ESCO memiliki nilai $P$-Value sebesar 0,043 , dan CN2 memiliki nilai $P$-Value sebesar 0 . Nilai $P$ Value semakin mendekati nilai 1 berarti parameter sangat sensitif terhadap perubahan nilai variable yang diuji. Hasil kalibrasi menunjukan nilai parameter yang paling sensitif dalam pembentukan besarnya debit aliran sungai yaitu SURLAG

\subsection{Validasi Model}

Hasil validasi model (Gambar 5) didapatkan nilai $P$-factor sebesar 0,36 ( $P$-value $<0.8)$, artinya sebanyak $36 \%$ debit observasi berada atau berpotongan dengan debit hasil simulasi model. Sedangkan nilai $R$-factor yang didapat yaitu sebesar 0,91 ( $R$-factor < 1). Selanjutnya, nilai koefisien NSe sebesar 0,64, dan nilai $\mathrm{R}^{2}$ sebesar 0,74 . Berdasarkan persyaratan yang tertera pada proses kalibrasi nilai NSe sudah cukup baik karena berada pada rentang nilai 0,54-0,65, sedangkan untuk nilai $\mathrm{R}^{2}$ dikatakan baik karena $>=0,6$ (Amin, 2015).

Persebaran nilai $\mathrm{R}^{2}$ dapat dilihat pada Gambar 6 . Hasil validasi tersebut menunjukkan bahwa model SWAT dapat dipergunakan untuk memprediksi kondisi hidrologi DAS Way Sekampung Hulu.

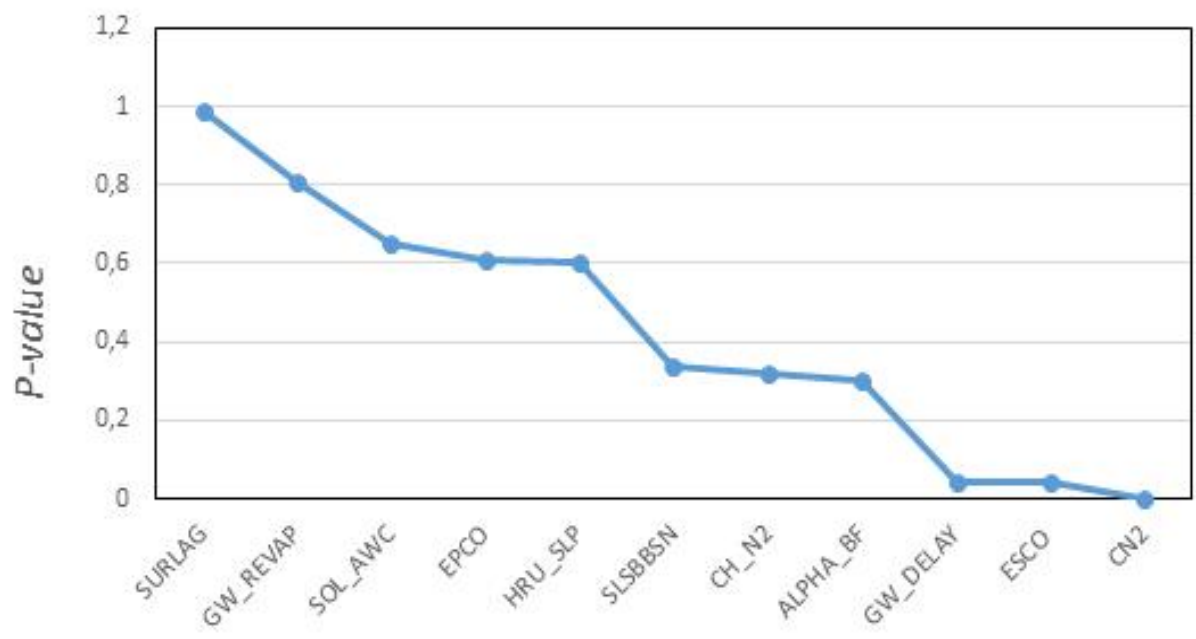

Gambar 4. Grafik Analisis Sensitivitas Parameter Hasil Kalibrasi

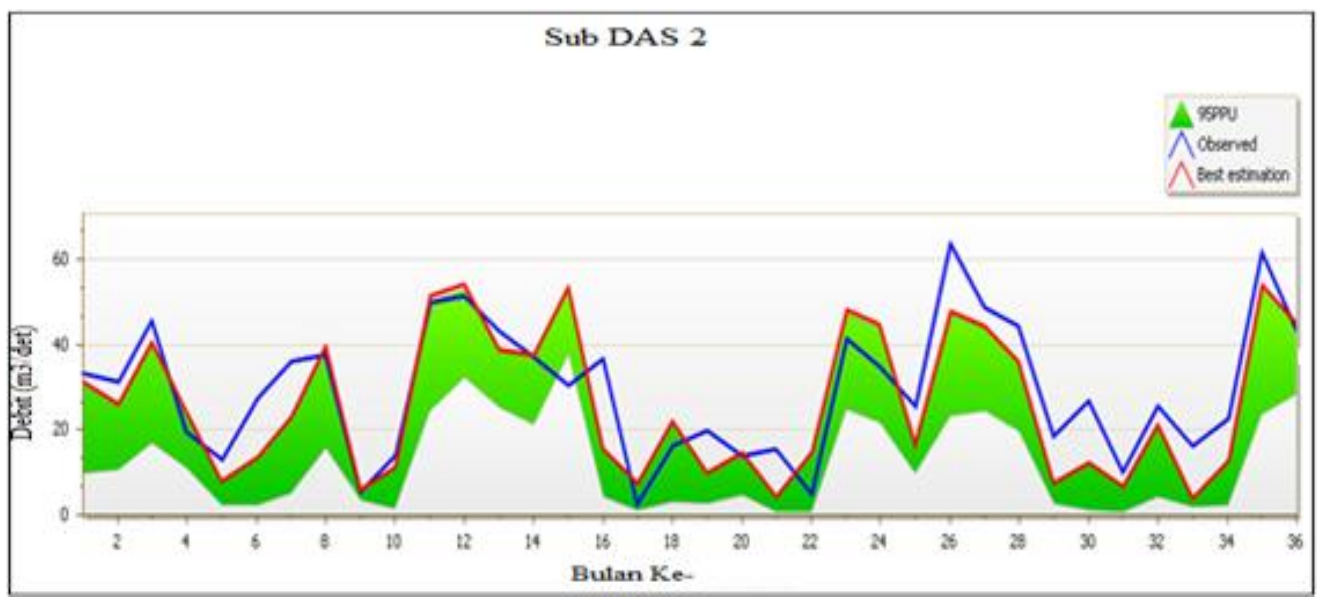

Gambar 5. Perbandingan Debit Observasi dan Debit Model Hasil Validasi 


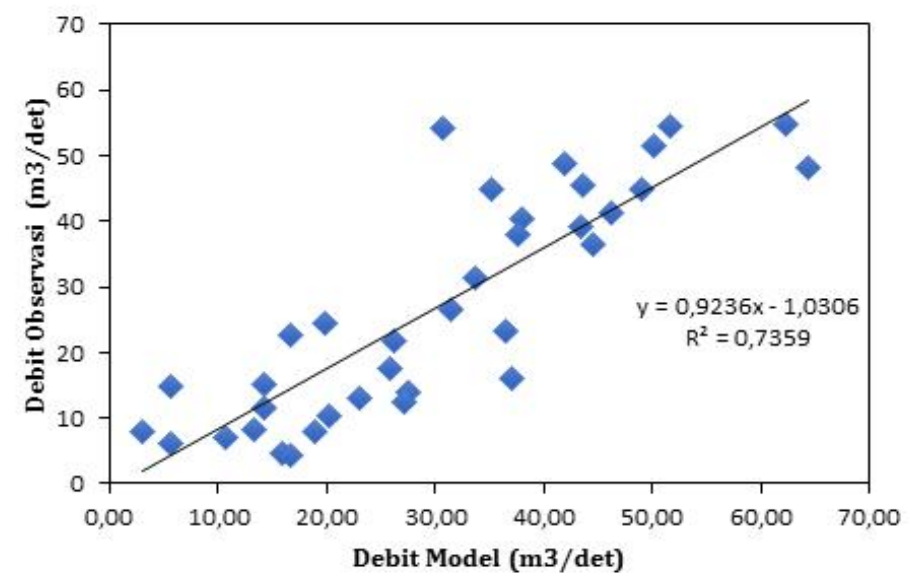

Gambar 6. Grafik XY Scatter antara Debit Observasi dan Debit Model

Tabel 2. Nilai Koefisien Aliran Permukaan (C) untuk Setiap Penggunaan Lahan

\begin{tabular}{llcccc}
\hline \multirow{2}{*}{ No } & \multirow{2}{*}{ Penggunaan Lahan } & \multicolumn{2}{c}{$\mathbf{2 0 1 0}$} & \multicolumn{2}{c}{$\mathbf{2 0 1 5}$} \\
\cline { 3 - 6 } & & \multirow{2}{*}{ SubDAS 1 } & SubDAS & SubDAS & \multirow{2}{*}{ SubDAS 2 } \\
\hline 1 & Pemukiman & 0,22 & 0 & $\mathbf{1}$ & \\
2 & Semak Belukar & 0,13 & 0,13 & 0,13 & 0,22 \\
3 & Hutan Lahan Kering Primer & 0,11 & 0,11 & 0,11 & 0,13 \\
4 & Tanah Terbuka & 0 & 0 & 0,44 & 0,43 \\
5 & Tegalan & 0 & 0,27 & 0 & 0,28 \\
6 & Perkebunan & 0,15 & 0,16 & 0,16 & 0,15 \\
\hline
\end{tabular}

Sumber : Analisis SWAT, 2017.

\subsection{Analisis Koefisien Aliran Permukaan} Hasil analisis bentuk penggunaan lahan tahun 2010 dan tahun 2015 pada DAS Way Sekampung Hulu, menunjukkan telah terjadi perubahan luas penutupan lahan pada DAS. Perubahan penggunaan lahan berhubungan erat dengan terjadinya aliran permukaan. Berdasarkan hasil analisa HRU pada setiap Sub DAS, diperoleh nilai koefisien aliran permukaan pada setiap jenis penggunaan lahan sebagaimana disajikan pada Tabel 2.

Berdasarkan Tabel 2 dapat diketahui besarnya nilai koefisien aliran permukaan (C) rata-rata pada setiap jenis penggunaan lahan. Nilai $C$ untuk semak belukar yaitu 0,13 yang berarti sebanyak $13 \%$ dari total curah hujan yang jatuh di atas semak belukar akan mengalir sebagai aliran permukaan. Nilai C rata-rata untuk jenis penggunaan lainnya yaitu perkebunan sebesar 0,15 , pemukiman sebesar 0,22 , hutan lahan kering primer sebesar 0,11 , tegalan sebesar 0,27 dan tanah terbuka sebesar 0,44. Hasil analisis tersebut menunjukkan bahwa semakin terbuka lahan maka jumlah air hujan yang menjadi limpasan permukaan akan semakin besar dan sebaliknya semakin tertutup lahan akan semakin kecil. Hasil penelitian ini sejalan dengan teori pendugaan volume limpasan permukaan sebagaimana dikemukakan oleh Delmar, D., dkk. (2006).

\section{KESIMPULAN DAN SARAN}

\subsection{Kesimpulan}

1. Hasil penelitian memberikan nilai koefisien aliran permukaan (C) hutan lahan kering primer sebesar 0,11 , semak belukar memiliki nilai $C$ sebesar 0,13 , perkebunan sebesar 0,15 , pemukiman sebesar 0,22 , tegalan sebesar 0,28 dan tanah terbuka sebesar 0,44 yang berarti bahwa semakin rapat penutupan lahan oleh vegetasi akan memiliki nilai koefisien $\mathrm{C}$ yang lebih kecil dan sebaliknya penutupan lahan yang semakin terbuka akan memiliki nilai koefisien $\mathrm{C}$ yang semakin besar.

2. Model SWAT dapat digunakan untuk menduga kondisi hidrologis DAS Way Sekampung Hulu dengan hasil cukup memuaskan jika menggunakan nilai parameter SURLAG 
sebesar 0,389, GW_REVAP sebesar 8,451, SOL_AWC sebesar 1,104, EPCO sebesar 0,008, HRU_SLP sebesar 0,898, SLSBBSN sebesar 23,195, CH_N2 sebesar 3,876, ALPHA_BF sebesar 0,636, GW_DELAY sebesar 8,451, ESCO sebesar 1,335, dan CN2 sebesar 1,979.

\subsection{Saran}

1. Untuk mendapatkan gambaran nilai koefisien limpasan permukaan (C) yang lebih bervariasi maka dalam proses pembentukan HRU dalam model SWAT disarankan menggunakan batas minimal luasan variable pembentuk HRU yang berbeda.

2. Untuk mendapatkan nilai tolak ukur uji kalibrasi dan validasi (NSe dan R2) yang lebih tinggi disarankan menambah jumlah simulasi pada setiap iterasi.

\section{DAFTAR PUSTAKA}

Amin, M. 2015. Simulasi Tata Guna Lahan Untuk Pengelolaan DAS Garang Jawa Tengah. (Disertasi). Universitas Gadjah Mada. Yogyakarta.

Badan Meteorologi Klimatologi dan Geofisika. 2017. Departmen Pekerjaan Umum. Direktorat Sumber Daya Air. Lampung.

Balai Besar Wilayah Sungai Mesuji-Sekampung. 2017. Departmen Pekerjaan Umum. Direktorat Sumber Daya Air. Lampung.

Broto, A. H. 2009. Kajian Perubahan Penutupan Lahan dan Arahan Pengelolaan Ruang Daerah Tangkapan Air (DTA) Waduk Batutegi Kabupaten Tanggamus Provinsi Lampung. (Tesis). Institut Pertanian Bogor.

Dahtiar, R. 2015. Analisis Debit Aliran Sungai Dengan Model SWAT di DAS Cisadane Hilir, Provinsi Banten. (Skripsi). Departemen Teknik Sipil dan Lingkungan, Institut Pertanian Bogor.

Delmar, D. F., William, J., Stephen, R., Rodney, L., Glen, O. Schwab. 2006. Soil and Water Conservation Engineering. $5^{\text {th }}$ edition. Clifton Park. New York. 502 pages.
Rau, M. I. 2012. Analisis Debit Sungai Dengan Menggunakan Model SWAT Pada DAS Cipasauran, Banten. (Skripsi). Fakultas Teknologi Pertanian, Institut Pertanian Bogor. 
Analisis koefisien aliran permukaan.... (Danesta AS, Ridwan, Mohamad A dan Sandi) 